Gut, 1967, 8, 169

\title{
Recovery, reproducibility, and usefulness of polyethylene glycol, iodine-labelled rose bengal, sulphobromophthalein, and indocyanine green as non-absorbable markers
}

\author{
WILLIS C. MADDREY, HAROLD A. SEREBRO, HELEN MARCUS, AND \\ FRANK L. IBER \\ From the Division of Gastroenterology, Department of Medicine, Johns Hopkins University School of Medicine, \\ Baltimore, Maryland, U.S.A.
}

EDITORIAL COMMENT All of these markers except indocyanine green were completely recovered in the dog.

Non-absorbable reference markers are widely employed in investigations of gastrointestinal absorption either to estimate the fluid content of a segment of gut or to compare the concentration of the markers to that of an unknown (Cooper, Levitan, Fordtran, and Ingelfinger, 1966; Clifton and Schedl, 1963; Fordtran, Levitan, Bikerman, Burrows, and Ingelfinger, 1961; Schedl, 1966). The reliability of both estimations has been questioned (Worning and Amdrup 1965). The need in our laboratory for a highly precise determination of the fluid content of the rat intestine led to this re-evaluation. Data in the literature on recovery of the indicator and the reproducibility upon serial sampling of the intestinal contents from the same site are limited (Cooper et al., 1966; Schedl, 1966). The total recovery and constancy on serial sampling of four different markers has been investigated in dogs with Thiry-Vella loops.

\section{METHODS}

Four mongrel dogs were prepared with Thiry-Vella loops by the method of Markowitz, Archibald, and Downie (1954) utilizing a $30 \mathrm{~cm}$. loop of jejunum (dogs A, B, C) or ileum $(\operatorname{dog} D)$. One week was allowed for postoperative recovery of dogs $\mathrm{A}, \mathrm{B}$, and $\mathrm{C}$ and to allow the loop to stabilize. Dog D was studied on the day of operation, two days, and 13 days later. Plaster of paris collars were found to be effective in preventing the dog from tearing at the loop with his teeth. Dog A was studied six times over a 92-day interval, dog B was studied twice 12 days apart, and $\operatorname{dog} \mathrm{D}$ was studied three times in 15 days.

On the day of study the dog was placed supine and lightly anaesthetized with intravenous sodium pentobarbital ( 5 to $7.5 \mathrm{mg}$./kg. body weight). Foley catheters (size no. 24) with $30 \mathrm{ml}$. occlusive balloons were used in both ends of the loop. They were positioned manually and the catheters held immobile with clamps to prevent leakage. The loop was initially perfused with 200 to $300 \mathrm{ml}$. of isotonic saline to wash it free of accumulated mucus and cell debris. All perfusion was made with a Technicon roller pump delivering $10.6 \mathrm{ml} . / \mathrm{min}$. When the effluent became clear, a sample was collected for blank determinations. While washing was taking place a stock solution of indicators was prepared. To isotonic saline $(750 \mathrm{ml}$.) was added sufficient polyethylene glycol (P.E.G.), ${ }^{1}$ sulphobromophthalein (B.S.P.) ${ }^{2}$, indocyanine green (I.C.G.) ${ }^{2}$ or ${ }^{131}$ I labelled rose Bengal (R.B.) to give an approximate final concentration of P.E.G. $25 \mathrm{mg}$./ml., I.C.G. 0.0067 mg./ml., B.S.P. $0.033 \mathrm{mg} . / \mathrm{ml}$. , and R.B. 10,000 counts/ min./ml. In some studies $10 \%$ mannitol was substituted for isotonic saline (see Table I).

After collection of the blank effluent the intake tubing to the perfusion pump was placed in an exactly measured quantity of stock indicator solution. An aliquot of the stock indicator is retained for analysis as a standard.

The effluent was then continuously collected in a beaker. A few minutes after the green colour of I.C.G. was first noticed in the effluent (approximately 10 minutes after onset) a $20 \mathrm{ml}$. sample was taken from the outlet tubing. Nine subsequent $20 \mathrm{ml}$. samples were taken. Each sample required about two minutes of flow and five minutes of flow separated each small sample. All effluent was collected, either in the large pooled sample or in the 10 individual samples. When all of the stock solution had been infused, isotonic saline was added to the pump reservoir to wash all of the stock through the pump and into the loop. Washing was continued with isotonic saline until at least 15 minutes after all colour had disappeared from the effluent. These washings were collected as a separate pool and analyzed. Duplicate determinations 1P.E.G. supplied as Carbowax 4000. Union Carbide Corporation. ${ }^{2}$ B.S.P. and I.C.G. supplied by Hynson, Wescott \& Dunning, Incorporated, Baltimore, Maryland 21201. 
were performed on each sample and quadruplicate determinations were made on each large pool. From the measured volumes of the samples the total amount of each material recovered in the samples and washings could be determined.

Polyethylene glycol was measured by the method of Hyden (1956). Sulphobromsulphalein determinations were performed on a Beckman DU spectrophotometer at 580 $\mathrm{m} \mu$ (Seligson, Marino, and Dodson, 1957). Indocyanine green was determined on the Beckman DU spectrophotometer at $800 \mathrm{~m} \mu$. The R.B. was counted in a Picker automated well scintillation counter. All samples used for B.S.P. and I.C.G. determinations were subjected to centrifugation before analysis. Mucus was present in many samples and it was observed that the blue-green colour of I.C.G. often adhered to the mucus. Alkalinization of the mucous plug did not bring out the colour of B.S.P. No method was devised to quantitate the amount of I.C.G. lost in this way.

\section{RESULTS USING RECOVERY DATA}

In Table $\mathrm{I}$ is listed the percentage recovery of each marker in each of the 12 experiments. The means and standard deviations of the means (corrected for small sample) indicate that the recovery is less than $100 \%$ only for I.C.G. The standard deviation and coefficient of variation

$$
\text { (C.V. } \left.=\frac{100 \times \text { Standard Deviation }}{\text { Mean }}\right)
$$

are greatest for P.E.G.

\section{TABLE I}

PERCENTAGE RECOVERY OF MARKERS FROM THIRY-VELLA LOOPS

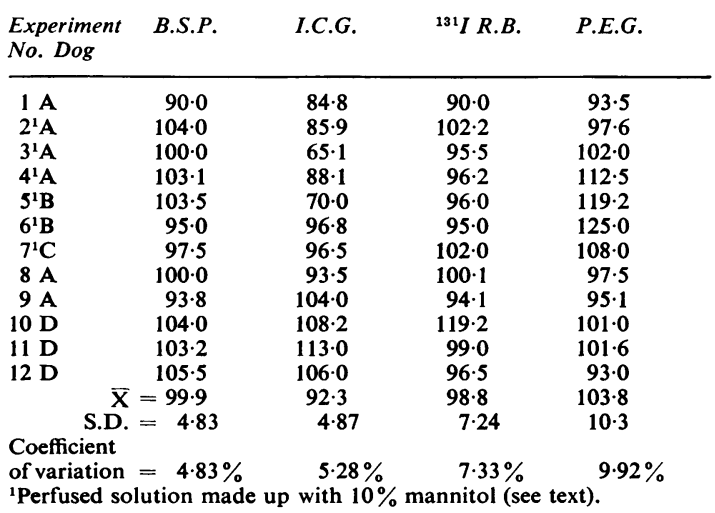

\section{STATISTICAL ANALYSIS USING 10 SAMPLES IN EACH STUDY}

EFFECT OF TIME OF SAMPLE ON CONCENTRATION OF INDICATOR AFTER ONSET OF PERFUSION Within a given experiment each timed marker concentration was compared to the mean and standard deviation for all of the data. This analysis for each of the four substances indicated that the time of sampling was not significant at $\mathbf{P}<0 \cdot 01$.

COMPARISON OF EXPERIMENTS IN SEPARATE DOGS All data for each dog were reduced to means. No significant difference $(\mathrm{P}<0.01)$ was found between dogs.

COMPARISON OF STUDIES IN THE JEJUNUM WITH THOSE IN THE ILEUM Again, the data for each dog reduced to means were compared and no significant difference $(\mathrm{P}<0.01)$ was found between experiments done in the jejunum and those in the ileum.

COMPARISON OF STUDIES WITH $10 \%$ MANNITOL AND THOSE DONE IN ISOTONIC SALINE No significant differences $(P<0.01)$ were found between studies employing $10 \%$ mannitol and those with isotonic saline.

PARTIAL CORRELATION OF VARIABLES Table II gives the partial correlation (correlation between two variables when a series of other variables is held constant) between marker pairs (Fisher, 1956). Significant correlation was found between R.B. and P.E.G. and between B.S.P. and R.B. That between R.B. and P.E.G. is almost complete.

TABLE II

PARTIAL CORRELATION BETWEEN PAIRS OF MARKERS

B.S.P. and I.C.G. (R.B. and P.E.G.-constant) $=0.0161$ B.S.P. and R.B. (I.C.G. and P.E.G.-constant) $=0.7619$ B.S.P. and P.E.G. (I.C.G. and R.B.-constant) $=0.4861$ I.C.G. and R.B. (B.S.P. and P.E.G.-constant) $=0.4287$

I.C.G. and P.E.G. (R.B. and B.S.P.-constant) $=0.1742$

R.B. and P.E.G. (B.S.P. and I.C.G.)-constant) $=0.9902^{1}$ ${ }^{1}$ Significant (Fisher, 1956).

Tables III, IV, V, and VI present the mean and standard deviation for each marker in the 12 experiments corrected to an arbitrary standard to account for slight differences in initial infusate concentrations. The coefficient of variation from animal to animal is $<1 \%$ for each marker.

\section{TABLE III}

SUMMATION OF VARIABILITY OF B.S.P.

\begin{tabular}{|c|c|c|c|}
\hline $\begin{array}{l}\text { Experiment No. } \\
\text { Dog }\end{array}$ & Mean $^{1}$ & S.D. & $\begin{array}{l}\text { Coefficient of } \\
\text { Variation }(\%)\end{array}$ \\
\hline $1 \mathrm{~A}$ & $6 \cdot 16$ & $0 \cdot 18$ & $2 \cdot 8$ \\
\hline $2 \mathrm{~A}$ & $6 \cdot 16$ & $0 \cdot 18$ & 3.0 \\
\hline $\mathbf{3 A}$ & $6 \cdot 16$ & $0 \cdot 30$ & 4.9 \\
\hline $\mathbf{4 A}$ & 5.91 & 0.09 & 1.6 \\
\hline $5 B$ & $6 \cdot 16$ & 0.02 & 2.9 \\
\hline $6 \mathrm{~B}$ & $6 \cdot 17$ & 0.02 & 4.8 \\
\hline $7 \mathrm{C}$ & $6 \cdot 16$ & 0.03 & $4 \cdot 7$ \\
\hline $\mathbf{8 A}$ & $6 \cdot 16$ & $0 \cdot 18$ & 2.9 \\
\hline $9 A$ & $6 \cdot 17$ & $0 \cdot 20$ & 2.7 \\
\hline 10D & $6 \cdot 67$ & $0 \cdot 10$ & 1.4 \\
\hline $11 \mathrm{D}$ & $6 \cdot 17$ & 0.23 & $3 \cdot 7$ \\
\hline \multirow{3}{*}{\multicolumn{4}{|c|}{ ${ }^{12 D}$ units $/ 20 \mathrm{ml}$.- corrected mean of 10 samples. }} \\
\hline & & & \\
\hline \multirow{2}{*}{\multicolumn{4}{|c|}{$\begin{aligned} \mu & =6.19 \\
& =0.05\end{aligned}$}} \\
\hline & & & \\
\hline \multicolumn{4}{|c|}{ C.v. $= \pm 0.79 \%$} \\
\hline
\end{tabular}


